\title{
The development of $\mathrm{O} 2 \mathrm{O}$ system of resource sharing courses for the discipline of optical engineering in China
}

Xu Liu, XiangDong Liu, XiaoDong Zheng, XiaoPing Wang, YuanFang Lin

Xu Liu, XiangDong Liu, XiaoDong Zheng, XiaoPing Wang, YuanFang Lin, "The development of $\mathrm{O} 2 \mathrm{O}$ system of resource sharing courses for the discipline of optical engineering in China," Proc. SPIE 9793, Education and Training in Optics and Photonics: ETOP 2015, 97930J (8 October 2015); doi: $10.1117 / 12.2223071$

Event: Education and Training in Optics and Photonics: ETOP 2015, 2015, Bordeaux, France 


\title{
The development of $\mathrm{O2O}$ system of resource sharing courses for the discipline of Optical engineering in China
}

\author{
Xu Liu, XiangDong Liu, XiaoDong Zheng, XiaoPing Wang and YuanFang Lin \\ State key laboratory of Modern Optical Instrumentation \\ Dept. of Optical Engineering, Zhejiang University, Hangzhou 310027, China
}

\begin{abstract}
In this talk, we are going to present our new try to set up National Optical Education Small Private Online Course (SPOC) system, which relates about 15 universities who has optical engineering education around China. The SPOC system is guided by the National Teaching Steering Committee, and is designed to enhance the sharing the best teaching and training resources in the advanced university to the other universities all over the China.
\end{abstract}

Keywords: high education, optical engineering education, SPOC

\section{INTRODUCTION}

The high education in China has been developed so rapidly in the last 20 years. There are more than two thousand universities and colleges now in CHINA, among them, more than 220 universities and colleges have disciplines in the field of optics and photonics, for example the discipline of optical engineering, optics and photonics or the disciplineof optoelectronics etc.. These universities and colleges have different student's qualities levels (big difference in national university entrance examination score) and different education training objectives, and in current state some universities or college even in poor education conditions, not only teachers quality, but also experimental condition. In China, the high quality teaching resources (including teachers and textbook, and program and experiment etc. are concentrated in the $15 \%$ top university, and $90 \%$ students are distribute in the other $85 \%$ universities). Face to this situation, the Ministry of Education of China has organized"The Ministry of Education Teaching Steering Committee"to coordinating the high education of the different universities all over the country in each discipline. Teaching Steering Committee is composed by the famous experts of the best universities, academic institutions and famous industries in China, and they are asked to investigate the situation of university education of the corresponding discipline in China, and give suggestion to the Ministry of Education, about the evaluation of research, advice, guidance, assessment, services on undergraduate teaching and so on. The main tasks of the committee are:

- To organize and conduct theory and practice of undergraduate teaching.

- To provide advice and recommendations to the Ministry of Education on the work of professional disciplines colleges and universities, teaching materials, teaching laboratory construction and teaching reform.

- To develop the professional standards of education or the quality of teaching standards.

- To evaluate the undergraduate teaching program and consulting Undergraduate education.

- To organize teacher training, academic discussions and exchange of information and so on.

- To undertake other tasks commissioned by the Ministry of Education.

The Steering committee of optics and photonics (SCOP) discipline was set up in 2013. The task of SCOP is to organize all the universities and colleges who has the discipline in optics and photonics together, to found a big optics and photonics undergraduate education and teaching community, exchange the teaching experience, design the national teaching program standard in the discipline, evaluate the teaching program and curricular, present the advice or policy to the Ministry, and speed up the undergraduate education quality in the field of optics and photonics in China.

The SCOP has proposed to set up a project: the National Optical education Small Private Online Course (SPOC) system for optics and photonics discipline, to enhance domestic optical education. We call that SPOC system as the "Tele resource sharing courses for the discipline of Optical engineering in China". We think it is a good technique that can profit the top teaching resources in China to the general student all over China. In This paper, we try to present our first period try in the project.

Education and Training in Optics and Photonics: ETOP 2015, edited by Eric Cormier, Laurent Sarger Proc. of SPIE Vol. 9793, 97930J · C 2015 SPIE, IEEE, OSA, ICO · doi: 10.1117/12.2223071 


\section{TELE RESOURCE SHARING COURSES SYSTEM}

\subsection{The Concept of On-line to Off-line Teaching Resource Sharing System}

We have just mentioned that in China there are about 220 universities and colleges have set up the discipline in Optics or Photonics, they has basic teaching resource for the students, but they are eagerly to profit the high quality teaching resource of hole China.

How to do it? We try to use a special MOOS system to share the best high quality teaching resource of optics and Photonics in China. If MOOCs are used as a supplement to classroom teaching rather than being viewed a replacement for it, they can increase instructor leverage, student throughput, student mastery, and student engagement. This is the model of SPOC: small private online course. Figure 1 show out the difference between MOOCS and SPOC systems.

To design a SPOC system, organize the best teaching resource ( the professor and textbook, course ware, excises experiments etc.) together, to found a high education base for optics and photonics.

We use of online courses (similar MOOC) curriculum of minority students enrolled in the school real implementation. And we choose the small number of school registration (s), in addition to online video and exercises, etc., can also be assisted under other online or offline classroom answering." So that we design this our Tele Teaching resource sharing courses by an On line to Off line SPOC system ( or O2O system).

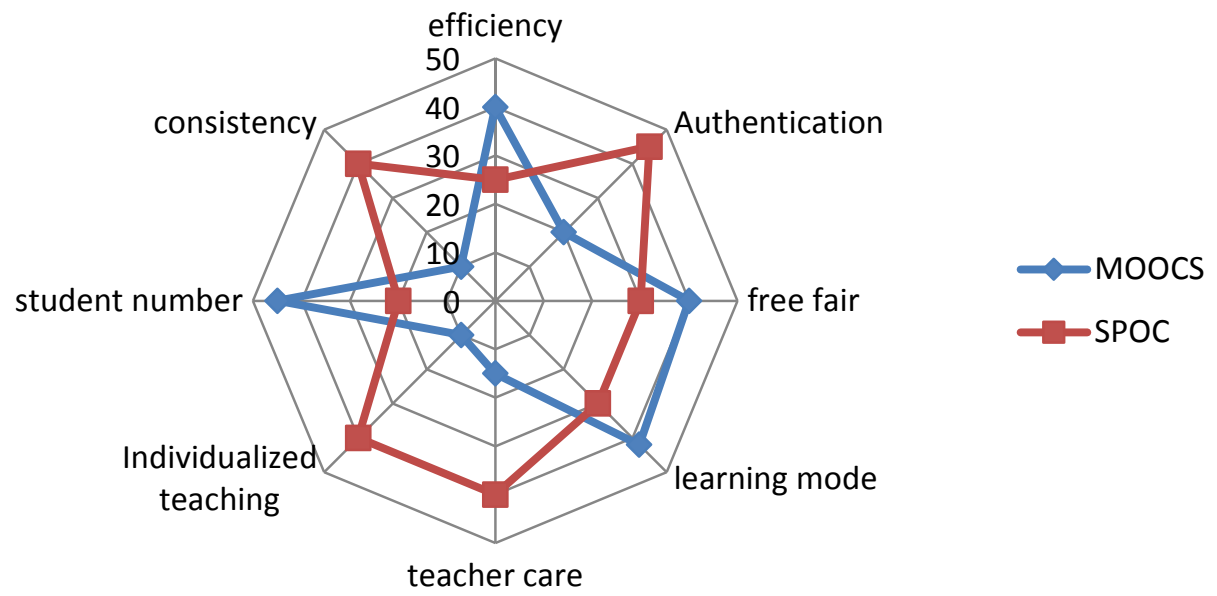

Figure 1 The difference between the SOPC and MOOCs

\subsection{National Optical Education Small Private Online System}

For setting up the National Optical education SPOC system, we have first choose some common courses which are general courses that will be adapted in the education program of the most universities. So that we choose the most general course: "Applied Optics" (AO) and " Principle of Microprocessor and Interface Technology" (PMIT) two courses for the essay.

As the pilot courses, we invited the best professors of the two courses, and choose the universities to joint this project. Table 1 show out the current universities joint in the SPOC project. Each university will have same education Syllabus for these two courses, and can acts as the resource offer or resource receiver, sometime both offer and receiver.

We have to design the education process, and the rule for the SPOC education. For resource provider side, the university must open the teacher resource and open the courseware, exercise and homework, experiment etc. to the receiver side, and then send the professor of the course to each receiver side for review the education performance, especially the understanding or mastering result of the receiver side student, and also hold question class in the receiver side. For the receiver, the university has to ask their own teacher to prep learn the course resource form the course's offer, and then guided their own student take the on line course, the student will to do the same home work as the offer' side student, and will take same examination in the off line course.

Some time, the receiver side can just choose individual content use the SPOC system, and the other part is by the conventional education method. 
Table 1. The participants of National Optical education SPOC

\begin{tabular}{|c|l|c|}
\hline Courses & \multicolumn{1}{|c|}{ Participants } & Roles \\
\hline AO,PMIT & Zhejiang University & provider/receiver \\
\hline AO & Tianjin University & provider \\
\hline AO & Changchun University of Science and Technology & provider/receiver \\
\hline AO & Beijing Technical college & provider/receiver \\
\hline AO, PMIT & Chongqing University & receiver \\
\hline AO & Wuhan University & receiver \\
\hline AO & Sichuan University & receiver \\
\hline PMIT & Xiamen University of Technology & receiver \\
\hline PMIT & Beijing Information Science \& Technology University & receiver \\
\hline PMIT & Jimei University & receiver \\
\hline AO & Fujian Normal University & receiver \\
\hline AO & Zhejiang Normal University & receiver \\
\hline AO, PMIT & Nanchang Hangkong university & receiver \\
\hline AO,PMIT & Xi an Technological University & provider/receiver \\
\hline AO & Yanshan University & provider/receiver \\
\hline AO,PMIT & Dalian University & receiver \\
\hline AO,PMIT & Huazhong University of Science and Technology & provider/receiver \\
\hline AO & National University of Defense Technology & provider/receiver \\
\hline AO, PMIT & China Jiliang University & receiver \\
\hline PMIT & Zhejiang Sci-Tech University & receiver \\
\hline
\end{tabular}

\subsection{Tele-experiment}

How to do the tele experiment? It is an important aspect of train and teaching resources. We have design a system try to realize the tele experiment. The tele-experiment system must satisfy following aspects:

1) It must be remote controllable

2) It must be present the as similar as possible feeling of doing the experiment

3) It can be repeatable, and will be fully recorded in process

4) It can show out the results visually

We have to design the experimental system, by using all digital driven system for the optics components alignment, and measurement, and also video capture system to capture the consequence of the remote adjustment in real time.

\section{PRIMARY ATTEMPT AND CURRENT STATE}

The primary attempt of the National Optical education SPOC system began from early 2014, We just chose "Applied Optics" to act as the essay. Three universities were joint in the project: Zhejiang University (ZJU), Nanchang Hangkong University (NCHKU) and Changchun University of Science and Technology (CCUST). Prof. Cen and Prof. Li from ZJU acted as provider, and there were 17 students joint the program. There are 30 students of CCUST take part in as the receiver side, but they just take two Chapters' contents learning form SPOC. As for NCHKU, one class students (62 students) participate the SPOC learning, the students just take on line course, and the local teacher act as course counselling and question course. Prof. Cen and Prof.Li not only just gave the on line course, but also gave off line Q course through the net. Figure 2 shows some course situation and the courseware on the net. 


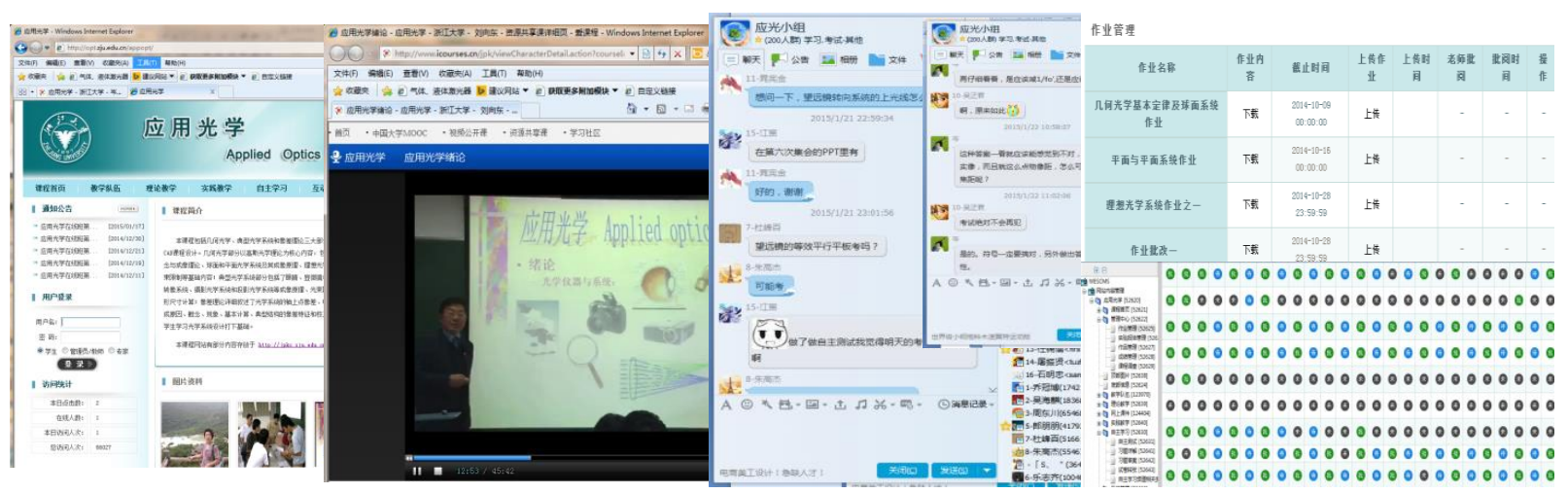

Figure 2 The web side, course, off line question chat, homework checklist of AO course

Current, the National Optical education SPOC system has entering second step, there are more than 20 universities to join the program. And we choose two courses to act as the SPOC courses. With enough student participant samples, we can find out the education result of our special SPOC system with the traditional local classroom local teacher teaching system.

We have also designed a prototype tele-curriculum experiment system: the focus length measurement of an objective. This is an experiment in course of Applied Optics. The principle of the measurement is shown in figure 3(a) . We use the motor driven translation plate to move the objective and use CMOS device to replace reading microscope.

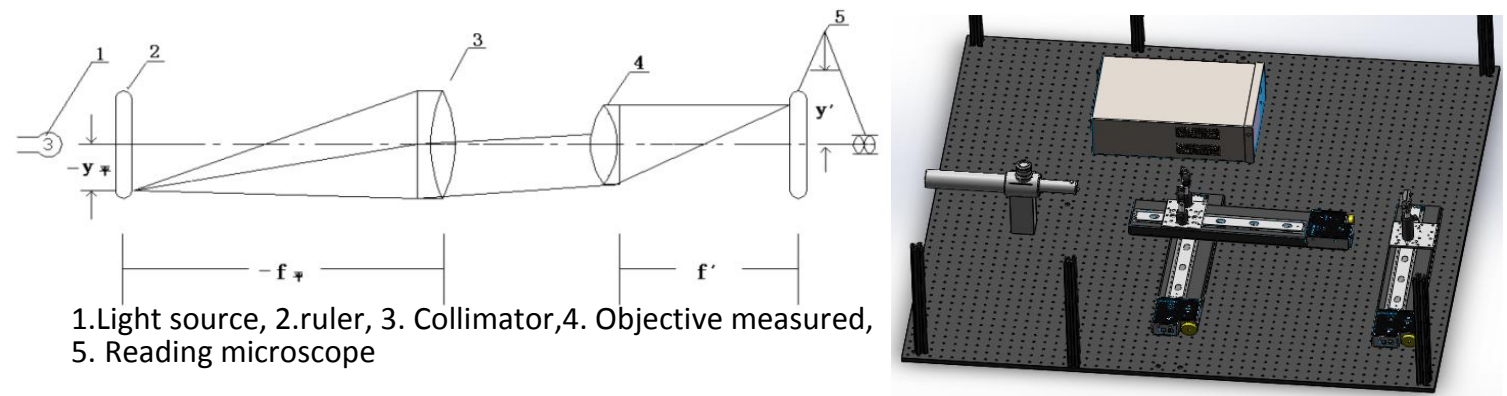

Figure 3. The principle of Tele- curriculum experiment system

\section{CONCLUSIONS}

How to use the quality teaching resource to most universities and most students is an important topic in the modern high education, especially in the developing country. We propose a National Optical education SPOC system try to realize this dream. We are in the essay, we have made some progress, but we know it is not easy, because it will challenge the current university resource, and the profit of the different, and also the teaching style of the teacher. We are going to do our best.

\section{ACKNOWLEDGEMENTS}

This project is a national project, about 15 universities are joint in the project, we would like to thank Prof. YG Fu, Prof. D M Liu, Dr. Z Y Liu of Changchun University of Science and technical university, Prof. Z F Cen, and Prof X T Li of Zhejiang University and Prof. X. D He, Prof. S.P Wan of Nanchang Hangkong University for the support on promotion the SPOC system.

\section{REFERENCES}

1. http://www.icourses.cn/coursestatic/course_6800.html

2. http://opt.zju.edu.cn/appopt

3. http://jpkc.zju.edu.cn/k/548

4. http:// www.cnspoc.com /school/opt

5. Li Xiaotong, Cen Zhaofeng, Liu Xiangdong, et.al., The resource sharing course applied optics: Flipped class model and MOOC-like construction, Proc. of 2014 national conference in optical and photo-electric professional education and teaching reform[C], The Ministry of Education Teaching Steering Committee of Optics and Photonics 2013-2017. Qinhuangdao, China, 2014: 1-5 